British Journal of Education, Society \&
Behavioural Science
$13(1): 1-11,2016$, Article no.BJESBS.20535
ISSN: 2278-0998
SCIENCEDOMAIN international
www.sciencedomain.org

\title{
Academic Plagiarism: Yielding to Temptation
}

\author{
Maria João Ferro ${ }^{1 *}$ and Hélder Fanha Martins ${ }^{1}$ \\ ${ }^{1}$ Lisbon Polytechnic Institute, Lisbon Accounting and Business School (LABS - ISCAL), Portugal.
}

Authors' contributions

This work was carried out in collaboration between both authors. Both authors read and approved the final manuscript.

Article Information

DOI: 10.9734/BJESBS/2016/20535

(1) Stan Weeber, Professor of Sociology, McNeese State University in Lake $\frac{\text { Editor(s): }}{\text { Charles, }}$

Louisiana, USA

Reviewers:

(1) Sanja Tatalović Vorkapić, University of Rijeka, Croatia.

(2) Anonymous, University of Nevada Reno, USA.

(3) Anonymous, Universiti Putra Malaysia, Malaysia.

Complete Peer review History: http://sciencedomain.org/review-history/11969

\section{Review Article}

Received $31^{\text {st }}$ July 2015 Accepted $8^{\text {th }}$ October 2015 Published 24 ${ }^{\text {th }}$ October 2015

\begin{abstract}
Scope: Everybody lies. Plagiarism is pervasive because people are used to lying to succeed. While bringing up someone else's ideas may be an inadvertent case of cryptomnesia, or unintentional plagiarism, academic plagiarism is hardly ever that case. Building on the existing literature, the aim of this paper is twofold. On the one hand, it contributes to the creation of a new framework for the definition of academic plagiarism within the larger scope of academic dishonesty, or academic misconduct; on the other hand, it identifies forms to recognize and discourage it.

Aim: Our aim is to provide the basis for a subsequent empirical study on the phenomenon of plagiarism at LABS-ISCAL hoping to help diminish this practice that is deeply rooted in students in general.
\end{abstract}

Keywords: Academic misconduct; academic dishonesty; cryptomnesia; plagiarism.

\section{INTRODUCTION AND ORIGIN OF THE TERM}

Plagiarism, presently often associated with the widespread use of the Internet, is not a recent phenomenon, nor should it be considered outside the context of a specific culture. Even in the Western world, imitation was seen as an acceptable literary device, of which many classical authors - such as Homer, Plato, 
Socrates, and Aristotle - made extensive use [1], consisting then in an appropriate form of praising former work by great authors. This way of viewing imitation - or mimesis as the Greeks called it - has to be properly taken into account when dealing with students from different origins, since for them plagiarism can be 'grounded in different notions of respect for authority and different traditions of academic writing' [2].

Given that the aim of this paper is to contribute to the creation of a new framework for the definition of plagiarism and identify forms to fight it in the context of Portuguese higher education institutions, we shall use a standard modern Western view of plagiarism as an undesirable practice from which students must be discouraged. To start with a very basic definition of the concept to which students may readily have access, according to the Encyclopaedia Britannica online, plagiarism is 'the act of taking the writings of another person and passing them off as one's own'. This very idea of appropriation of someone's possessions can be felt in the term itself: Barnhart dates the etymology of the word plagiarism ('literary theft'), from the earlier English word plagiary ('one who wrongfully takes another's words or ideas'), resulting from the Latin plagarius ('kidnapper, seducer, plunderer, literary thief'), from plagium (kidnapping) from plaga (snare, net) [3]. The definition goes on to ascertain that this fraudulent act 'is closely related to forgery and piracy - practices generally in violation of copyright laws', which brings us to Gutenberg and the printing press, the first great revolution in terms of authorship rights.

When Gutenberg provided the world with the printing press in the 1440's suddenly it became much easier to uncover similarities between written texts. And what was formerly seen as a form of flattery or something which could be laughed at became more than a nuisance for the plagiarized authors. The Protestant ideals of originality and individual thought as opposed to the omnipresence of the fathers of the church and strict Catholic conventions 'advanced the notion that individual authorship was good and that mimesis was bad' [1]. The first copyright laws - passed in England in 1710 and in the United States in 1790 - laid the grounds for writing as a trade and opened the authors' eyes to each and every possibility of having been plagiarized [1]. Plagiarism was thus born out of the legal notion of copyright [4] and authors have been protected against it by a series of laws, which culminated in the Berne Convention for the Protection of Literary and Artistic Works implemented in 1886 and revised and amended many times ever since.

\section{PLAGIARISM IN THE SOCIETY AT LARGE}

'Everybody lies'. This is, in fact, the opening sentence for Saltzman's [5] argument that plagiarism is pervasive in society because people are used to lying to succeed. Saltzman [5] adds that '[l]ying has become such an integral part of society that no one seems outraged by it anymore'. The truth is that authors do feel outraged and every year numerous cases are filed against alleged plagiarists. The arts in general are a source of much litigation over copyrights. A simple Google search will yield dozens of cases of confirmed plagiarism in music and literature. Many cases, however, are dismissed not only due to the thin line that separates fraud from inspiration or recreation, but also due to the concept of 'cryptomnesia' or 'inadvertent plagiarism' [6]. Sometimes plagiarism can be unintentional, i.e., we can envisage ideas, images, sounds as our own creations when in fact we have been exposed to them elsewhere. According to the MerriamWebster online dictionary, cryptomnesia is 'the appearance in consciousness of memory images which are not recognized as such but which appear as original creations'. Cryptomnesia thus lacks the intentionality and consciousness of plagiarism and is, according to Sacks [7], a preferable term for this phenomenon. Even though we may call plagiarism 'unconscious', the word plagiarism 'is so morally charged, so suggestive of crime and deceit, that it retains a sting even if it is "unconscious"' [7].

In the Western society plagiarism is seen as an evil, a wrongful deceptive act that undermines trust and compromises the credibility of the confirmed plagiarists. However, the same society that so openly condemns plagiarism is often too forgiving when their idols are at stake. See, for instance, how easily Rod Stewart has been forgiven by his fans even after the court considered him guilty of copyright infringement, which he himself acknowledges in his autobiography [8].

Other tacit forms of accepted plagiarism $[9,10]$ include 'institutional plagiarism', by which a person takes credit for the work done by others, such as reports or co-authored papers, when the 
work was mostly done by subordinates or students respectively, and speeches written by speechwriters for politicians.

\section{ACADEMIC PLAGIARISM: DEFINITION}

While cryptomnesia can be used as an explanation for apparent plagiarism in music or literature, it can hardly be used as an excuse by students who copy whole sections of papers or Internet blogs without altering the text or mentioning its source. Nevertheless, we should not jump at our students' throats whenever we have to mark a plagiarized paper, since there are several types of plagiarism and it can simply be the case that students are not aware they need to mention their sources.

For a working definition of academic plagiarism, let us use the Council of Writing Program Administrators [11]:

In an instructional setting, plagiarism occurs when a writer deliberately uses someone else's language, ideas, or other original (not common-knowledge) material without acknowledging its source. [...] This definition applies to texts published in print or on-line, to manuscripts, and to the work of other student writers.

This definition however presents at least two loopholes that students can take advantage of: The notion of 'deliberately' using someone else's material and the definition of 'commonknowledge'. In the first case, students can - and do - argue that they were not aware that those were the ideas of so and so, that they did not even know of the existence of that person in particular. If their argument holds true, then it can be mere coincidence or a case of cryptomnesia. The problem is how to prove whether students were aware they were plagiarizing or not. This is particularly troublesome when we are considering ideological plagiarism, i.e., when we are talking about stealing someone else's ideas. Explicit plagiarism, on the other hand, is quite easy to identify and quite hard to justify - it implies copying the exact words of another author. When students copy full paragraphs or even full sentences, a Google search will render the original, but this distinction becomes blurred when we are talking about strings of words. Some University guidelines on avoiding plagiarism go as far as saying that a string of five equal words may be considered plagiarism (see, for example, University of Arizona, [12], and Newham College [13]).

Obviously, some common sense is needed when assessing students' papers, given that some fiveword phrases are quite ordinary and do not constitute a case of plagiarism. The same could be said for a string of even more words such as the definition for common knowledge widely found on the Internet, whose original source we were unable to find: 'facts that can be found in numerous places and are likely to be known by a lot of people.'

Common knowledge is therefore the other grey area as far as academic plagiarism is concerned. Students find it difficult to distinguish what is common knowledge from what is information they need to provide references for. Neville [14] states that common knowledge needs to be seen from two perspectives:

(i) Knowledge in the public domain: information that refers to undisputed facts, freely and publicly shared, not subjected to copyright law and not derived from opinion; general descriptions of folklore and traditions; common place observations, or aphorisms.

(ii) Knowledge that is common to a specific subject area or field of studies.

While the former refers to knowledge that is common to everyone, the second refers to knowledge that circulates freely within a field of studies. Students need to be advised as to what constitutes common knowledge in their specific subject area and should be encouraged to use references when in doubt as to whether a specific information is common knowledge in their area or not.

Another important distinction needs to be done between plagiarism and inadequate referencing. If students do make an effort to credit their sources, but fail to use the specific citation format or quotation marks, they should not be accused of plagiarism but simply of having 'failed to cite and document sources appropriately' [15]. Although she recognizes that plagiarism violates the rules of academic conduct, Pecorari makes a linguistic analysis of the issue, arguing for an approach centred on teaching academic writers how to use sources properly instead of focusing on the penalties that should be applied to those that do not conform to the rules [15]. 
Sutherland-Smith's model of the 'plagiarism continuum' [4] offers a good groundwork for improving our working definition, taking into consideration that plagiarism is an elastic concept that depends on the way different institutions and even different fields of knowledge perceive it and that ha been evolving through the ages.

Thus, we view academic plagiarism in the context of business studies as a form of academic dishonesty that occurs when the writer intentionally or unintentionally uses someone else's words, ideas or other material without properly referencing the source. The seriousness of the misconduct depends on the intention of the writer and therefore has to be dealt with accordingly.

\section{PLAGIARISM AS A FORM OF ACADEMIC DISHONESTY}

Academic dishonesty, or academic misconduct, takes many forms. It ranges from cheating in an exam to explicit plagiarism. Students are often not aware that, for instance, if they let someone else copy from their exam they are also guilty of cheating and not only the person who copied from them [16]. Over the course of the last 10 years working with postgraduate students who are conducting their research and preparing to write dissertations we have observed and carried out informal interviews that have allowed us to have a preliminary grasp on forms of academic dishonesty including the following (see Table 1):

Martin [10] describes academic plagiarism, or 'competitive plagiarism' as he terms it, as a struggle between perpetrators and opponents, where students (the perpetrators) try to get away with deceiving their teachers, who will dutifully oppose - or try to oppose - their plans. When the perpetrators are weak, i.e., when they commit the offense of plagiarizing word by word, what we will call 'explicit plagiarism', they will be easily caught. In contrast, catching stronger opponents, i.e. those that usurp ideas and not words - 'ideological plagiarism' - is far more difficult.

\section{TYPES OF PLAGIARISM}

Academic plagiarism - both explicit and ideological - comes in many shapes and guises, which usually fit into any of the following four categories shown in Table 2.

Students are usually aware that acquiring readymade material instead of writing the assignment themselves is wrong. However, they feel that the chances of being caught are slim and therefore worth the risk. This means that either asking someone to write their assignment for them or using material they obtain somehow - be it through an online paper mill, an article they find

Table 1. Types of academic dishonesty

\begin{tabular}{lll}
\hline $\begin{array}{l}\text { Exam } \\
\text { (Test or similar) }\end{array}$ & $\begin{array}{l}\text { Paper } \\
\text { (Or other assignment) }\end{array}$ & Other forms \\
\hline $\begin{array}{l}\text { Receiving or providing } \\
\text { information during the exam. }\end{array}$ & $\begin{array}{l}\text { Having another student write } \\
\text { the paper or write the paper for } \\
\text { another student. }\end{array}$ & Plagiarism. \\
\hline Using unauthorized notes. & $\begin{array}{l}\text { Taking credit for someone } \\
\text { else's work. }\end{array}$ & Inadequate use of references. \\
\hline $\begin{array}{l}\text { Gaining previous access to a } \\
\text { copy of the exam. }\end{array}$ & $\begin{array}{l}\text { Submitting the same paper } \\
\text { (or a similar version) to more } \\
\text { than one subject. }\end{array}$ & Paraphrasing inadequately. \\
\hline $\begin{array}{l}\text { Gaining previous access to the } \\
\text { answer key. }\end{array}$ & Fabricating data. & Manipulating faculty. \\
\hline $\begin{array}{l}\text { Having another student sit the } \\
\text { exam or sit the exam for another } \\
\text { student. }\end{array}$ & Receiving unpermitted help. & $\begin{array}{l}\text { Fabricating excuses for non- } \\
\text { compliance with dates of exams } \\
\text { or papers. }\end{array}$ \\
\hline $\begin{array}{l}\text { Using any unauthorized device or } \\
\text { another form of study aid during } \\
\text { an exam. }\end{array}$ & $\begin{array}{l}\text { Unauthorized collaborative } \\
\text { work. }\end{array}$ & $\begin{array}{l}\text { Preventing other students from } \\
\text { completing their tasks. }\end{array}$ \\
\hline \multicolumn{2}{c}{ Source: based on the authors' ongoing research } \\
\hline & Buying papers to submit. & $\begin{array}{l}\text { Falsifying information or data on } \\
\text { academic records. }\end{array}$ \\
\hline
\end{tabular}


Table 2. Categories of academic plagiarism

1. Using material from another source:

(a) Buying a paper from a research service, essay bank or term paper mill (either pre-written or specially written);

(b) Copying a whole paper from a source text without proper acknowledgement;

(c) Submitting another student's work, with or without that student's knowledge.

2. Submitting a paper written by someone else (e.g. a peer or relative).

3. Copying sections of material from one or more source texts, supplying proper documentation (including the full reference) but leaving out quotation marks, thus giving the impression that the material has been paraphrased rather than directly quoted.

4. Paraphrasing material from one or more source texts without supplying appropriate documentation.

Source: adapted from Park [2]

on the Internet or someone else's paper - are the two 'safest' ways of cheating without much risk of being punished.

While the first two categories would be immediately recognized by any student as plagiarism, that is not the case with the third and fourth categories. In fact, many students believe that if they mention the source text on the bibliography of their paper they are not plagiarizing. And that if they change the wording of the source text they are not plagiarizing. These two types of plagiarism are generally easier to spot, but much more difficult to eradicate. In fact, even when the institution has a strict anti-fraud policy that imposes severe punishments on plagiarists, if the students are not aware they are plagiarizing, they will not abstain from doing it.

On a side note, we should also mention that although lecturers are usually seen as role models by their students, many cases of selfplagiarism have been working their way through the academia, which means we need to start thinking about healing from the inside. Although 'self-plagiarism' is a controversial term, we use it here to encompass a series of academic misconducts faculty members are sometimes accused of, such as publishing the same paper in two or more publications (dual or duplicate publication) or 'slicing up' their findings and transforming them into several publications instead of a single one (salami publishing), among others. In an extended editorial Martin [17] provides examples of such behaviour found in papers submitted to (and some even published on) Research Policy in recent years, while Andreescu [18] and Robinson [19] discuss the term self-plagiarism and find that it is a misnomer, since you can hardly steal from yourself. Robinson offers to call it a case of 'unfortunate publication' thus relieving it from the heavy burden the word plagiarism carries with it.

\section{THE IMPORTANCE OF CORRECT REFERENCING}

'If I have seen further it is by standing on the shoulders of giants.' Isaac Newton, 1676.

Students are expected to refer to the sources of words, ideas, data and other pieces of information they rely upon when writing an academic paper. Citing an author is not only a form of paying homage to the giants that have shaped our way of thinking, but also to grant credibility to our work by supporting it on the shoulders of others that have come before us. Although it would be far-fetched to call referencing an art, it is useful to take some time to clarify to students not only the standard used for references in the institution where they are studying providing extensive examples, but also to explain the difference between bibliography all the works they have read while doing the assignment - and references - only the works they have actually quoted on their assignment. This basic distinction is the foundation for a correct referencing of the sources provided that there is an accurate match between what the students say they did and what they have actually done. Falsifying bibliographies, for example, is a common trick employed by students to have teachers believe they have researched hard on the subject when they have based their research on a couple of papers.

Sometimes students believe they should not mention all the works they have read so their work does not seem a patchwork of copied and pasted ideas. Many students, in fact, express their fear that lecturers will disregard their work if they see too many names in brackets or too 
many quotation marks. As a guide for anxious students, Neville [14] provides six cases in which referencing is essential.

1. Disclosing the source of tables, statistics, diagrams, photographs and other illustrations.

2. When describing or discussing a theory, model or practice associated with a particular writer.

3. To give weight or credibility to an argument.

4. When giving emphasis to a particular theory, model or practice that has found a measure of agreement and support among commentators.

5. To provide sources of direct quotations or definitions.

6. When paraphrasing another person's work, which is outside the realm of common knowledge, and that is particularly significant or likely to be a subject of debate.

Depending on the institution's practice, incorrect referencing may be considered plagiarism and therefore penalized as such or it can simply be deemed a matter of ignorance on the part of the student, who will be admonished without any further punishment.

\section{PLAGIARISM IN THE DIGITAL ERA}

When asked to write an assignment, students will typically set off on an Internet search googling a few keywords to get them jumpstarted. However, a considerable number of students will then rely on their copy-paste skills to save them time and thinking effort.

While academic cheating in the form of buying papers, for example, is not a new phenomenon [20], with the Internet this practice has boomed. Many websites - term paper mills - offer readyto-go papers at affordable prices, which are, however, easier to catch given that different students may end up buying the same paper to hand in to the same teacher. Those who can afford to pay more will find customized services that will produce from minor 30-page papers to full master dissertations or doctoral theses. These services are publicly offered, widely available over the WWW and there is not much instructors can do to prevent or expose these cases since proving the student has bought the paper is an almost impossible task.

Students believe it is acceptable to put technology to good use when it comes to helping them with their poor time management skills, but they fail to realize that when they are copying and pasting they are not actually learning, they are not researching - 'writing papers and creating presentations involves not simply locating information but reading, paraphrasing, summarizing, and synthesizing from multiple sources to formulate their own ideas into a new product' [21]. It is essential to make students aware that when it comes to writing a paper - or a dissertation for that matter - their added-value is to establish connections between what they have read and to write a good literature review that will accurately portray the state-of-the-art and that may thus serve as a springboard to new research papers.

\section{HOW TO IDENTIFY PLAGIARISM}

Besides using specific software to detect plagiarism - such as Approbo, Ephorus, or Copycatcher - which may or may not be available for the lecturer, there are straightforward forms to identify this type of fraud:

When instructors suspect a case of plagiarism, they usually search for a statistically improbable phrase in the paper and google it. There is much debate as to the number of words that constitute plagiarism. In fact Crawford [22] argues we should not rely completely on this method, given that most sentences contain language that is so common that it renders them totally ineffective for the detection of plagiarism. Even so, Crawford [23] ends up ascertaining that it is highly improbable for a 10-word string to appear more than once.

However, instead of looking at plagiarism detection software as a means to discourage misconduct based on the fear of ensuing sanctions, there is a recent trend of viewing this as a plagiarism prevention tool. Löfström \& Kupila [24], for example, argue for the use of plagiarism detection software as a pedagogical tool that can be used by both students and lecturers to promote desirable ethical behaviour.

\section{WHY DO STUDENTS PLAGIARIZE?}

Although detecting plagiarism is vital, knowing why this phenomenon happens is even more important to designing a solution for this problem. Table 4 summarizes the main reasons that have been found to explain the prevalence of plagiarism today. 
The first category of reasons for plagiarism is sheer ignorance: some students simply do not know how to quote, paraphrase or provide accurate references, or they do not have a clear understanding of the phrases 'common knowledge' and 'in your own words'. In this view, plagiarism can be seen as an acceptable mistake, which is part of the learning process.

Secondly, we have to take into account time management issues. Students have all sorts of academic tasks, besides the peer pressure to have an active social life, play sports and take up other academic activities, or even in some cases provide support to their families. With all that is going on in an undergraduate student's life, lack of time is clearly a problem. When there is a poor notion of time and a lack of planning, plagiarism seems an easy way out, reducing the time and effort needed to complete tasks. Procrastination is a major issue for some people and students who procrastinate, who start completing their assignments later than they should, will not have enough time to finish them properly and will engage in some sort of academic misconduct such as fabricating excuses so that the lecturer extends the deadline or straight out plagiarizing. Patzrek et al. [25], in fact, found that academic procrastination has a direct impact on three types of misconduct: Fraudulent excuse making, plagiarism and cheating in exams.

Table 3. Common ways to identify plagiarism

\begin{tabular}{|c|c|c|}
\hline Speech & Data & Research \\
\hline Sudden changes in speech. & $\begin{array}{l}\text { Incomplete } \\
\text { data. }\end{array}$ & $\begin{array}{l}\text { Too much sophistication for the student in } \\
\text { particular or for the level of knowledge the } \\
\text { students are supposed to have at that stage. }\end{array}$ \\
\hline Obvious translations. & $\begin{array}{l}\text { 'Perfect' } \\
\text { data. }\end{array}$ & $\begin{array}{l}\text { Research and conclusions that do not coincide } \\
\text { with the methodology described. }\end{array}$ \\
\hline Extemporaneous excepts. & & $\begin{array}{l}\text { Impossibility of carrying out the research in the } \\
\text { amount of time available. }\end{array}$ \\
\hline $\begin{array}{l}\text { Widely known ideas, theories, } \\
\text { terminology (that do not follow into } \\
\text { the category of common } \\
\text { knowledge). }\end{array}$ & & \\
\hline
\end{tabular}

Source: Based on the authors' ongoing research

Table 4. Reasons for plagiarism

\begin{tabular}{l}
\hline \multicolumn{1}{c}{ Genuine ignorance } \\
\hline Fearning process \\
Feeling that plagiarizing will result in a higher grade than if the student completed the assignment \\
by herself \\
Efficiency gains \\
Time management issues \\
Personal values and attitudes \\
Disrespect \\
Challenge \\
Attitudes of students towards lecturers and the class \\
Feeling that the lecturers will not recognize plagiarized text \\
Denial or neutralization \\
Temptation and opportunity \\
Tasks that are too generic/theoretical/complicated \\
Lack of consequences \\
Feeling that their classmates do it \\
Cultural differences \\
Feeling that everything on the Internet is public
\end{tabular}
Source: Adapted from Park [2]; Council of Writing Program Administrators

[11]; Comas-Forgas, Sureda-Negre [26] 
Some students simply do not consider plagiarism an ethical issue, they believe means justify the ends and if they have to cut corners to have a better mark, then they will do it. In fact, most of these people do not feel any sort of shame and believe they are better than their peers because they are obviously smarter for tricking their instructors. Alongside with the social attitude towards condoning academic dishonesty, there is a sense of disrespect for the instructor, the course, the task at hand, the conventions on academic documentation or the consequences of their lack of ethics which is based on a general disrespect for authority or stems from the feeling that the task they were asked to perform is not important or sufficiently challenging.

Different from those that openly challenge authority are those who refuse to acknowledge their actions are wrong or that find ways to excuse their behaviour by blaming others. For these students, it is a matter of temptation and opportunity, since it is far easier to find, copy and paste information that is readily available over the Internet.

However, students should not solely be held responsible for yielding to temptation. Instructors have their share of the blame as well, since they assign generic tasks, year after year, for which students feel they are entitled to search for ready-made answers. Higher education institutions should reconsider their role since students feel that plagiarism goes unpunished given that there is a high probability of not being caught or of not being punished even when they are caught.

One last category to consider is the different notions according to culture. We have already mentioned that plagiarism has evolved in the Western culture along the centuries, but even today plagiarism is faced differently in different cultures. Asian students, for example, are typically thought to plagiarize for a number of reasons, including [27]: Respect and reverence for the authority, the disrespect and bad intellectual judgement implied on altering the authority's word, and even the duty felt within the Asian society to share knowledge with others. Conversely, in the Western culture, Martin [28] goes as far as to suggest that business education 'with its emphasis on economic theories and free markets' is indirectly encouraging students to plagiarize since this type of behaviour may give them the impression that they are maximizing their self-interests.

\section{CONSEQUENCES OF PLAGIARISM}

The worst consequence for plagiarists is the fact that they are hindering their future chances of success in life. Cheating may prevent them from actually learning anything or developing any meaningful work strategies, but also because research has found that the lack of academic integrity at school, mostly when it comes to higher education, is associated with a strong lack of professional integrity in the workplace $[29,30]$. In fact, students will have different perceptions of what is considered dishonest and what may be acceptable, which will shape their expectations regarding acceptable behaviour in their future professional lives [31].

Sanctions for plagiarism can range from getting a low grade, failing an assignment, failing the course, suspension or even expulsion, and depend on the institution. Although plagiarism and copyright infringement have several points of contact, the former rarely results in legal action, although some academic institutions warn students that plagiarists can be prosecuted. Conversely, several other instructors choose to turn a blind eye on this type of unethical misconduct, which sends an obviously wrong signal: 'we do students a substantial disservice when we don't treat academic dishonesty seriously - when we have overtly light penalties for serious ethical issues it communicates that they are not that serious' [32]. Each instructor individually and higher education institutions as a whole are under the obligation to seriously condemn any unethical behaviour in general and plagiarism in particular as part of the training the student is entitled to expect.

\section{HOW TO PREVENT AND AVOID PLAGIARISM}

The first step to avoid plagiarism is awareness: students have to be aware of what is considered plagiarism. Therefore, instructors and academic institutions need to go to great lengths to strengthen the idea that plagiarism is wrong but enriching one's assignment with the adequately referenced insights of other authors is right.

Educators can implement some strategies to help foster that perception of right and wrong as far as plagiarism is concerned (Table 5).

Students, on the other hand, need to be extra careful and check and recheck their assignments before they hand them in to make sure they have 
Table 5. How to deter plagiarism

Discuss with students standards of academic scholarship and conduct.

Make students aware of the importance of academic honesty.

Clearly state your policies and expectations for documenting sources and avoiding plagiarism.

Learn to recognize and act upon signs of stress in students.

Avoid using recycled or formulaic assignments that may invite stock or plagiarized responses.

Design assignments that require students to explore a subject in depth.

Ensure equal access to study materials.

Assure students they can succeed in your class without having to resort to dishonesty.

Confront students directly as soon as you suspect them of cheating or plagiarizing.

Clarify the distinctions between plagiarism, paraphrasing and direct citation.

Report possible cases of plagiarism to the institution.

Be aware of electronic plagiarism.

Source: Adapted from Davis [33] and Council of Writing Program Administrations [11]

\section{Table 6. How to avoid plagiarism}

Learn what plagiarism is and what it entails.

Face each assignment as a learning opportunity.

Distinguish between plagiarism, paraphrasing and direct citation.

Use the conventions for referencing established by the institution.

Assemble and analyse your own set of sources.

Clearly state when you are drawing on ideas of other authors, even if you are not using their words.

Identify direct citations with the exact page number.

Always provide references for:

ideas, opinions, theories;

facts, statistics, graphs, images;

direct written or oral speech;

paraphrases of direct written or oral speech.

Start your research early - you do not want to get caught up in the lack of time.

'When in doubt, don't' - always ask your instructor how to use contributions from other authors in your assignments when you are not exactly sure how to do it.

\section{Source: Based on the authors' ongoing research}

not committed any form of unintentional plagiarism. Table 6 (above) provides a series of guidelines that can help students in this task, which we have used extensively in postgraduate classes.

\section{CONCLUSION}

Plagiarism is something instructors have to live with - they are fully aware that each year several students will plagiarize or at least try to. Some will get caught, some will not. Academic institutions also share the task of preventing plagiarism, not only by issuing adequate guidelines and advertising them, but also by supporting instructors and acting upon any infringements that are reported. In fact, this is a major role, since '[c]ompliance with laws and regulations depends on the expected penalty facing violators. The expected penalty depends on both the probability of punishment and the severity of the punishment if caught.' [34]. If students realize they get away with a simple reprimand, they will continue with their behaviour. Therefore, one question remains: should instructors and institutions enforce stricter penalties for plagiarists, or should more attention be given to raising awareness for the importance of academic honesty?

We believe an in-depth study on higher education students at LABS-ISCAL (Lisbon Accounting and Business School) will provide useful insight not only to answer that question but also to design a more targeted set of guidelines to prevent and avoid plagiarism, given that the successful implementation of a wellcrafted academic integrity program can have a positive impact on business schools and improve the reputation of tomorrow's business leaders' [35]. Ethical issues should therefore be taken seriously by higher education institutions in general, and business schools in particular, given the recent financial scandals that have played a 
major role in creating a worldwide recession, thus diminishing the credibility of all those with a business education background [36].

In this paper we have provided our insights into the creation of a new framework for the definition of plagiarism that will guide us in the next step of our research: an empirical study conducted with graduate and undergraduate students to gauge their views on academic dishonesty in general and plagiarism in particular. Our final aim is to write a set of guidelines that will discourage academically dishonest behaviour and promote ethical practices.

\section{COMPETING INTERESTS}

Authors have declared that no competing interests exist.

\section{REFERENCES}

1. Hansen B. Combating plagiarism. CQ Researcher. 2003;13:773-796.

2. Park C. In other (people's) words: Plagiarism by university students literature and lessons. Assessment \& Evaluation in Higher Education. 2003;28(5):471-488.

3. Barnhart RK, editor. Chambers dictionary of etymology. Edinburgh: Chambers; 1988.

4. Sutherland-Smith W. Plagiarism, the Internet, and student learning: Improving academic integrity. New York: Routledge; 2008.

5. Saltzman J. The prevalence of plagiarism is the result of a dishonest society In: Williams $\mathrm{H}$, editor. Plagiarism. Farmington Hills: Greenhaven Press; 2008.

6. Carpenter S. Plagiarism or memory glitch? Inadvertent plagiarism complicates efforts to end cheating. Monitor. 2002;33(2):25.

7. Sacks O. Speak, Memory. The New York Review of Books. 2013;21.

8. Stewart R. Rod: The autobiography. London: Century; 2012.

9. Martin B. Plagiarism: A misplaced emphasis. Journal of Information Ethics. 1994;3(2):36-47.

10. Martin B. Plagiarism struggles. Plagiary: Cross-disciplinary studies in plagiarism, fabrication, and falsification. 2008;3. Accessed 27 April 2015.

Available:http://www.bmartin.cc/pubs/08pla giary.html [27/4/2015].

11. Council of Writing Program Administrators. Defining and avoiding plagiarism: The
WPA statement on best practices. Accounting Education News. 2004;32(1):58.

12. University of Arizona, Plagiarism - Don't even think of doing it! Accessed 23 July; 2014.

Available:http://ircamera.as.arizona.edu/Na tSci102/Plagiarism.pdf

13. Newham College, Avoiding plagiarism: Advice for students; Accessed 23 July; 2014.

Available:http://www.newn.cam.ac.uk/abou t-newnham/living-in-college/studenthandbook/content/avoiding-plagiarismadvice-for-students

14. Neville C. The complete guide to referencing and avoiding plagiarism. Berkshire: Open University Press; 2007.

15. Pecorari D. Academic writing and plagiarism: A linguistic analysis. London/New York: Continuum; 2008.

16. Jones L. Academic dishonesty, cheating, and plagiarism. Melbourne: Florida Institute of Technology; 2001.

17. Martin BR. Whither research integrity? Plagiarism, self-plagiarism and coercive citation in an age of research assessment. Research Policy. 2013;42(5):1005-1014.

18. Andreescu L. Self-plagiarism in academic publishing: The anatomy of a misnomer. Science and Engineering Ethics. 2013;19(3):775-797.

19. Robinson SR. Self-plagiarism and unfortunate publication: An essay on academic values. Studies in Higher Education. 2014;39(2):265-277.

20. Embleton K, Helfer DS. The Internet has made plagiarism easier for students. In: Williams $\mathrm{H}$, editor. Plagiarism. Farmington Hills: Greenhaven Press; 2008.

21. Lehman K. Stemming the tide of plagiarism: One educator's view. Library Media Connection. 2010;29(2):44-46.

22. Crawford W. How common is common language? Cites \& Insights. 2008;8(11):913.

23. Crawford $W$. The uniqueness of everyday language. Online. 2010;34(4):58-60.

24. Löfström E, Kupila P. The instructional challenges of student plagiarism. Journal of Academic Ethics. 2013;11(3):231-242.

25. Patrzek J, Sattler S, van Veen $F$, Grunschel C, Fries S. Investigating the effect of academic procrastination on the frequency and variety of academic misconduct: A panel study. Studies in Higher Education. 2015;40(6):1014-1029. 
26. Comas-Forgas R, Sureda-Negre J. Academic plagiarism: Explanatory factors from students' perspective. Journal of Academic Ethics. 2010;8(3):217-232.

27. Yusof DS. A different perspective on plagiarism. The Internet TESL Journal. 2009;15:2. Accessed 10 April 2015. Available:http://iteslj.org/Articles/YusofPlagiarism.html.

28. Martin DE. Culture and unethical conduct: Understanding the impact of individualism and collectivism on actual plagiarism. Management Learning. 2011;43(3):261273.

29. Sims R. The relationship between academic dishonesty and unethical business practices. Journal of Education for Business. 1993;68(4):207-211.

30. McCabe DL, Trevino LK, Butterfield K. The influence of collegiate and corporate codes of conduct on ethics-related behaviour in the workplace. Business Ethics Quarterly. 1996;6(4):461-476.
31. Kidwell LA, Kent J. Integrity at a distance: A study of academic misconduct among university students on and off campus. Accounting Education. 2008;17(1):3-16.

32. Kiviniemi MT. The case for consequences for academic dishonesty. College Teaching. 2015;63(2):37-39.

33. Davis BG. Preventing academic dishonesty. Tools for teaching. San Francisco: Jossey-Bass Publishers; 2009.

34. Friesen L. Certainty of punishment versus severity of punishment: An experimental investigation. Journal of Forensic Studies in Accounting \& Business. 2009;1(2):93112.

35. Caldwell C. A ten-step model for academic integrity: A positive approach for business schools. Journal of Business Ethics. 2010;92(1):1-13.

36. Floyd LA, Xu F, Atkins R, Caldwell C. Ethical outcomes and business ethics: Toward improving business ethics education. Journal of Business Ethics. 2013;117(4):753-776.

(c) 2016 Ferro and Martins; This is an Open Access article distributed under the terms of the Creative Commons Attribution License (http://creativecommons.org/licenses/by/4.0), which permits unrestricted use, distribution, and reproduction in any medium, provided the original work is properly cited.

Peer-review history:

The peer review history for this paper can be accessed here: http://sciencedomain.org/review-history/11969 